\title{
Produção e qualidade do leite em sistemas de produção da região leiteira de Pelotas, RS, Brasil
}

\author{
Milk yield and quality at production systems of the dairy region of Pelotas, RS, Brazil
}

\author{
Paulo Ricardo Garcia Martins ${ }^{\mathrm{I}}$ Vivian Fischer ${ }^{\mathrm{II}}$ Maria Edi Rocha Ribeiro ${ }^{\mathrm{III}}$ \\ Jorge Fainé Gomes ${ }^{\mathrm{III}}$ Waldyr Stumpf JrII Maira Balbinotti Zanela ${ }^{\text {IV }}$
}

\section{RESUMO}

O objetivo deste trabalho foi caracterizar a produção e a qualidade do leite em sistemas de produção da bacia leiteira de Pelotas. Entre setembro de 2001 e agosto de 2002, foram monitoradas, durante 11 meses, nove unidades produtoras de leite, classificadas nos seguintes sistemas de produção: especializado (ES), semi-especializado (SE) e nãoespecializado (NE). Em amostras coletadas no tanque resfriador, foram determinadas características físico-químicas do leite e contagem de células somáticas. O percentual de mastite e a e produção leiteira corrigida para $4 \%$ de gordura foram avaliados. Adotou-se o delineamento completamente casualizado em parcelas subdivididas. A crioscopia, apesar de apresentar diferença estatística entre ES e NE $(P<0,10)$, manteve-se dentro dos limites considerados normais. $O$ sistema ES apresentou menor percentual de mastite que SE e NE $(P<0,10)$. No entanto, a produção de leite corrigida para $4 \%$ de gordura, os teores de proteína, caseína, gordura, lactose, extrato seco desengordurado, extrato seco total, nitrogênio não-protéico, além da acidez titulável e da contagem de células somáticas, não apresentaram variação significativa entre os sistemas de produção. O maior grau de especialização permitiu menor percentual de mastite, contribuindo para a obtenção de leite com melhor qualidade.

Palavras-chave: características físico-químicas do leite, contagem de células somáticas, mastite.

\section{ABSTRACT}

This research was aimed at characterizing milk yield and quality of three production systems at Pelotas dairy region. From September 2001 up to August 2002, nine dairy production units were visited for 11 months. Production units were classified as specialized (S), partially specialized (PS) and non-specialized (NS). Bulk tank milk was sampled to analyze

\begin{abstract}
physical and chemical attributes and somatic cells count (SCC). Mastitis percentage and 4\% fat-corrected milk yield were evaluated. A completely randomized split-plot design was adopted. Cryoscopic index differed between specialized and non-specialized systems $(P<0.10)$, but all values were within the normal range. Specialized system showed lower mastitis occurrence than partially specialized and non-specialized systems $(P<0.10)$. Production systems did not differ for $4 \%$ fat-corrected milk yield, contents of protein, casein, fat, lactose, solids non-fat, total solids, non-protein nitrogen, as well as titrable acidity and somatic cells count. Higher technology level application reduced mastitis occurrence, contributing to a better milk quality.
\end{abstract}

Key words: mastitis, milk physical-chemical characteristics, somatic cells count.

\section{INTRODUÇÃO}

Existe um aumento na demanda global para a produção de leite de alta qualidade, devido à exigência do consumidor por maior segurança alimentar (MONARDES, 2004). Atributos como a composição química, as propriedades organolépticas (sabor, odor, aparência), o conteúdo microbiano, o número de células somáticas, a presença ou ausência de adulterantes e de contaminantes são, geralmente, referidos como parâmetros da qualidade do leite (RIBEIRO et al., 2000). Segundo a Instrução Normativa 51 (IN51), do Ministério da Agricultura, Pecuária e Abastecimento (BRASIL, 2002), implantada a partir de julho de 2005, os teores mínimos estabelecidos de gordura, proteína

\footnotetext{
I Programa de Pós-graduação em Zootecnia, Universidade Federal de Pelotas (UFPel), Pelotas, RS, Brasil.

IIDepartamento de Zootecnia, Universidade Federal do Rio Grande do Sul (UFRGS), Rua Fernandes Vieira 181/601, 90035-091, Porto Alegre, RS, Brasil. E-mail: vfried@portoweb.com.br. Autor para correspondência.

IIICentro de Pesquisas Agropecuárias de Clima Temperado, Embrapa, Pelotas, RS, Brasil.

${ }^{\mathrm{IV}}$ Departamento de Medicina Veterinária Preventiva, UFRGS, Porto Alegre, RS, Brasil.
} 
bruta e sólidos desengordurados para o leite cru refrigerado são, respectivamente, 3,0; 2,9 e 8,4\%. Na Região Sul, a contagem de células somáticas máxima será de um milhão de células/ml de leite de julho de 2005 a julho de 2008. O número de produtores que ficarão fora desses limites não está claro, pois existem poucos dados de caracterização da qualidade do leite nessa região.

A pecuária leiteira é uma das atividades mais importantes do setor agropecuário do Rio Grande do Sul, desenvolvida em $80 \%$ dos municípios gaúchos. No entanto, o setor leiteiro, tanto regional como local, apresenta problemas de eficiência produtiva e de qualidade de produto (BITENCOURT et al., 2000). O resultado dos sistemas de produção de leite depende da eficiência do gerenciamento do empreendimento, em seus aspectos técnicos, como manejo de alimentação, sanidade, qualidade do leite e de fatores econômico-financeiros (RIBEIRO et al., 2000).

Neste trabalho, objetivou-se estudar a variação da produção e da qualidade do leite na bacia leiteira de Pelotas, em função do sistema de produção adotado. Devido à existência de uma variedade muito grande de sistemas de produção, a identificação daqueles mais eficientes, tanto técnica como economicamente, é primordial para o estabelecimento de um programa de reestruturação do setor.

\section{MATERIAL E MÉTODOS}

Este trabalho foi conduzido pelo grupo de pesquisas “Estudos em Pecuária Leiteira”, da Universidade Federal de Pelotas, em conjunto com a Embrapa-Clima Temperado, em nove unidades de produção leiteira, pertencentes à região de Pelotas. Foram realizadas coletas mensais de leite, no período de 01/09/2001 a 31/08/2002 (com exceção do mês de janeiro). Ao final do período de coleta de dados, as unidades de produção leiteira foram classificadas em três sistemas de produção: sistema especializado (ES), semi-especializado (SE) e não-especializado (NE), determinados em função da quantidade e da disponibilidade de volumoso e de concentrado fornecidos, da infra-estrutura, do recebimento de assistência técnica e do tipo de ordenha.

A categoria ES foi constituída por três unidades de produção leiteira, sendo uma composta de um rebanho da raça Jersey e duas de rebanhos da raça Holandesa, com número médio de vacas em lactação superior a 25 animais especializados e selecionados à produção leiteira. Possuíam sala de ordenha tipo espinha de peixe, com circuito fechado, sala de espera pavimentada e sistema de limpeza dos equipamentos automatizado. Utilizavam medidas de controle de mastite, como caneca de fundo preto, préimersão em solução desinfetante, secagem dos tetos com papel toalha descartável, pós-imersão e descarte de animais portadores de mastite crônica. Utilizavam alimentação relativamente constante ao longo do ano, à base de concentrado com teor de proteína bruta médio de $16,80 \%$, silagem de milho ou sorgo e pastagem cultivada de forma intensiva, especialmente de aveia preta (Avena strigosa, Schreb) e azevém anual (Lolium multiflorum, Lam). As vacas foram inseminadas ou cobertas durante todo o ano, à medida que apresentaram cio, não havendo época definida ou restrita de parições.

A categoria SE foi constituída de quatro unidades de produção leiteira, constituídas da seguinte forma: uma composta por rebanho da raça Jersey e três por rebanhos da raça Holandesa, com número médio de vacas em lactação entre 15 e 20, sendo os animais considerados de boa aptidão leiteira. Duas unidades possuíam sala de ordenha espinha de peixe, com circuito fechado e duas utilizavam o sistema de balde ao pé. Nem todas as unidades de produção leiteira utilizavam todas as medidas de controle de mastite listadas para o sistema especializado. Utilizavam alimentação à base de concentrado, silagem de milho ou sorgo e pastagem de azevém anual (Lolium multiflorum, Lam), porém sem manter a qualidade e a constância durante o ano. As vacas foram inseminadas ou cobertas durante todo o ano, à medida que apresentaram cio, não havendo época definida ou restrita de parições.

A categoria NE foi constituída de duas unidades de produção leiteira, sendo uma composta por rebanho da raça Jersey e a outra por rebanho da raça Holandesa, possuindo em torno de 10 vacas em lactação, animais pouco especializados para produção leiteira. As duas unidades de produção utilizavam o sistema de balde ao pé. As medidas de controle de mastite não eram utilizadas ou apresentavam-se inadequadas. Não utilizavam ração balanceada nem silagem ou pastagem cultivada regularmente, e as condições nutricionais e sanitárias eram deficientes durante a maior parte do ano. As vacas foram cobertas durante todo o ano, à medida que apresentaram cio, não havendo época definida ou restrita de parições.

As amostras de leite foram coletadas do tanque resfriador, após a ordenha da tarde, e encaminhadas ao Laboratório de Nutrição Animal do Departamento de Zootecnia da Universidade Federal de Pelotas e para o Serviço de Análise de Rebanhos Leiteiros (Sarle) da Universidade de Passo Fundo, para a realização das análises físico-químicas. 
No início da ordenha da tarde, foram realizados testes da caneca de fundo preto e o "Califórnia Mastitis Test” (CMT), para detecção dos quartos mamários com mastite clínica e subclínica, respectivamente, em todas as vacas (SCHALM \& NOORLANDER, 1957). O percentual de mastite (MAS) foi calculado através da divisão do número de quartos positivos ao teste de CMT pelo número total de quartos analisados, em cada unidade de produção leiteira e a cada mês.

A avaliação das características químicas e físicas do leite foi feita pela determinação da acidez titulável, segundo o método de Dornic ( $\left.{ }^{\circ} \mathrm{D}\right)$; o teor de gordura foi determinado pelo método de Gerber (medida através do butirômetro de Gerber) (FAGUNDES, 1997), o extrato seco total (EST) foi determinado através do método de Ackermann (TRONCO, 1997) e o extrato seco desengordurado (ESD) foi calculado pela diferença entre a percentagem de gordura e extrato seco total (TRONCO, 1997). Os teores de nitrogênio não-protéico (NNP) e de proteína bruta (PB) foram determinados pelo método de Kjedahl (SILVA et al., 1997). A porcentagem de caseína (CAS) foi determinada através do método de Walker, utilizando $\mathrm{NaOH} 0,1 \mathrm{~N}$ e formaldeído (FAGUNDES, 1997). O teor de lactose (LACT) foi determinado através de espectrofotometria por leitura infravermelha no equipamento Bentley 2000® (BENTLEY INSTRUMENTS, 1995a). Os valores dos componentes químicos do leite foram apresentados como porcentagem. A crioscopia (CRIO) do leite foi medida através de Crioscópio Eletrônico Digital ITR MK540, fornecendo a leitura em Graus Horvet (TRONCO, 1997).

A contagem de células somáticas (CCS) foi realizada em contador eletrônico pela citometria de fluxo (Somacount 300®) (BENTLEY INSTRUMENTS, 1995b). Os resultados foram expressos como $\mathrm{n}^{\circ} \mathrm{x} 1.000$ células somáticas $\mathrm{mL}^{-1}$ de leite.

Foram coletadas amostras de todos os alimentos (concentrados, pastagem e silagem) utilizados no dia da coleta. Foram analisadas aquelas amostras relativas aos meses de outubro, março e agosto, por se julgar que esses meses seriam representativos da primavera, final do verão e inverno. No laboratório, realizou-se a pré-secagem das amostras, em estufa com circulação forçada de ar, à temperatura de $60^{\circ} \mathrm{C}$, por 48 horas, seguida por moagem em moinho tipo Willey. Posteriormente, foram analisadas quanto aos teores de proteína bruta, segundo o AOAC (1975), de fibra em detergente ácido (FDA) e fibra em detergente neutro (FDN) (GOERING \& VAN SOEST, 1970).

O delineamento experimental adotado foi o completamente casualizado em parcelas subdivididas
(MARKUS, 1973), considerando-se como parcela os sistemas de produção (GL=2), as unidades de produção leiteiras dentro de sistemas como resíduo $A(G L=6)$, os meses do ano como sub-parcelas $(\mathrm{GL}=10)$, a interação sistemas e meses $(\mathrm{GL}=20)$ e resíduo B $(\mathrm{GL}=60)$. Quando as interações entre sistemas e meses foram nãosignificativas, usou-se o resíduo A para testar o efeito de sistema. As variáveis dependentes analisadas foram os valores percentuais dos componentes químicos do leite, a crioscopia, a acidez, a produção de leite corrigida para 4\% de gordura, a percentagem de mastite e a contagem de células somáticas. A produção de leite do tanque foi corrigida para 4,0\% de gordura (NRC, 2001). Os valores de contagem de células somáticas foram transformados pela aplicação do logaritmo base 10 para posterior análise estatística (NG-KWAI-HANG et al., 1982). Foi utilizado o procedimento GLM do SAS (1989), e a separação das médias foi realizada pelo LSmeans (teste DMS de Fisher), com a probabilidade máxima de 0,10 para rejeição da hipótese de nulidade. Embora a análise estatística tenha sido feita com os valores transformados, os seus valores originais são apresentados nas tabelas que se seguem, para facilitar a interpretação. Os resultados relativos ao efeito dos meses do ano não são apresentados neste trabalho, mas foram abordados em outro manuscrito (MARTINS et al., 2006).

\section{RESULTADOS E DISCUSSÃO}

Não foram detectadas interações significativas entre meses e sistemas para as variáveis em estudo (Tabela 1). A produção de leite corrigida para 4\% de gordura (PLC) não diferiu estatisticamente entre os sistemas (Tabela 1), embora o sistema especializado se caracterizasse pela maior disponibilidade e melhor qualidade dos alimentos em relação aos demais (Tabela 2). Provavelmente a presença de um estabelecimento com menor produção leiteira, apesar das práticas adequadas de manejo, contribuiu para a não-detecção das diferenças. Na mesma bacia leiteira, GONZALEZ (2002) encontrou valores médios de PLC de 16,38; 9,32 e 5,91L vaca ${ }^{-1}$ dia $^{-1}$ e ZANELA et al. (2006) verificaram valores médios de PLC de 16,39; 10,73 e $5,88 \mathrm{~L}$ vaca $^{-1} \mathrm{dia}^{-1}$, respectivamente, para os sistemas especializado, semi-especializado e nãoespecializado. Esses valores foram distintos $(\mathrm{P}<0,05)$ entre os sistemas.

O índice crioscópico variou estatisticamente entre os sistemas (Tabela 1), mas esta diferença, na prática, não é relevante, já que todos os valores encontrados mantiveram-se dentro dos parâmetros considerados normais, $-0,530^{\circ} \mathrm{H}$ a $-0,560^{\circ} \mathrm{H}$ para leite 
Tabela 1 - Efeitos dos meses do ano, sistemas de produção e interação entre meses e sistemas sobre a produção de leite corrigida a 4\% de gordura (PLC) e as características físico-químicas do leite, seus valores médios e o número de amostras de leite que não se enquadram nas especificações da IN51, de acordo com os sistemas de produção especializado (ES), semi-especializado (SE) e nãoespecializado (NE).

\begin{tabular}{|c|c|c|c|c|c|c|c|}
\hline Atributos do leite & ES & $\mathrm{SE}$ & $\mathrm{NE}$ & Meses (P) & $\begin{array}{l}\text { Sistemas } \\
\text { (P) }\end{array}$ & $\begin{array}{l}\text { Sistemas X } \\
\text { meses (P) }\end{array}$ & $\mathrm{DP}^{6}$ \\
\hline PLC (L/vaca/dia) & 11,28 & 10,19 & 7,41 & 0,0001 & 0,2967 & 0,2555 & 2,31 \\
\hline Crioscopia $\left({ }^{\circ} \mathrm{H}\right)$ & $-0,538 b$ & $-0,541 a b$ & $-0,546 a$ & 0,0027 & 0,0581 & 0,1060 & 0,01 \\
\hline Acidez ( $\left.{ }^{\circ} \mathrm{D}\right)$ & 16,18 & 16,38 & 16,45 & 0,0001 & 0,9126 & 0,7740 & 1,08 \\
\hline Gordura (\%) & 3,55 & 3,06 & 3,21 & 0,1123 & 0,5960 & 0,7304 & 0,49 \\
\hline Lactose (\%) & 4,36 & 4,40 & 4,22 & 0,0001 & 0,4507 & 0,3649 & 0,13 \\
\hline Proteína (\%) & 3,21 & 3,04 & 3,11 & 0,0004 & 0,7662 & 0,1257 & 0,20 \\
\hline Caseína (\%) & 2,56 & 2,48 & 2,54 & 0,0001 & 0,8748 & 0,3067 & 0,17 \\
\hline $\mathrm{NNP}^{1}(\%)$ & 0,035 & 0,036 & 0,035 & 0,0890 & 0,7799 & 0,4346 & 0,01 \\
\hline $\operatorname{EST}^{2}(\%)$ & 11,95 & 11,43 & 11,45 & 0,0043 & 0,7853 & 0,8439 & 0,48 \\
\hline $\operatorname{ESD}^{3}(\%)$ & 8,41 & 8,37 & 8,24 & 0,0005 & 0,8921 & 0,8359 & 0,26 \\
\hline Mastite (\%) & $40,49 c$ & $51,14 b$ & $60,41 \mathrm{a}$ & 0,0001 & 0,0737 & 0,7940 & 12,03 \\
\hline $\mathrm{CCS}^{4}$ & 235 & 250 & 568 & 0,2980 & 0,1451 & 0,7129 & 176,36 \\
\hline \multirow[t]{2}{*}{$\mathrm{CCS}^{4,5}$} & 0 & 0 & 31,82 & - & - & - & \\
\hline & (0) & (0) & (7) & & & & \\
\hline \multirow[t]{2}{*}{ Gordura $^{5}$} & 27,3 & 45,5 & 31,8 & - & - & - & \\
\hline & (9) & (20) & (7) & & & & \\
\hline \multirow[t]{2}{*}{ Proteína bruta ${ }^{5}$} & 27,3 & 27,3 & 22,7 & - & - & - & \\
\hline & (9) & (11) & (5) & & & & \\
\hline \multirow[t]{2}{*}{$\mathrm{ESD}^{3,5}$} & 60,6 & 43,2 & 54,5 & & & & \\
\hline & (20) & (19) & (12) & & & & \\
\hline
\end{tabular}

${ }^{1}$ Nitrogênio não-protéico.

${ }^{2}$ Extrato seco total.

${ }^{3}$ Extrato seco desengordurado.

${ }^{4}$ Contagem de células somáticas (x $1.000 \mathrm{cel} / \mathrm{ml}$ ).

${ }^{5}$ Valores percentuais e números absolutos (entre parênteses) de amostras que não se enquadram nas especificações da IN51 até 2008 : CCS > 1.000 .000 células/ml, gordura $<3,0 \%$, proteína bruta $<2,9 \%$, sólidos desengordurados $<8,4 \%$. Os números totais de amostras consideradas foram de 33, 44 e 22, respectivamente, para os sistemas especializados, semi-especializado e não-especializado.

${ }^{6}$ Desvio-padrão.

a,b,c: médias seguidas por letras distintas diferem pelo teste DMS Fisher $(\mathrm{P}<0,10)$.

cru refrigerado (RODRIGUES, 2000), não acarretando em penalidade na formação do preço final do leite.

A acidez titulável não apresentou variação entre os sistemas (Tabela 1), e seus valores se situam dentro da faixa de variação normal (RODRIGUES, 2000), semelhantemente aos resultados encontrados por GONZALEZ (2002) e ZANELA et al. (2006) na mesma região, no período compreendido entre 09/1999 e 08/ 2001.

Não foram detectadas diferenças entre os sistemas para os valores percentuais de gordura, lactose, proteína, caseína e nitrogênio não-protéico, extrato seco total e extrato seco desengordurado (Tabela 1). Esse fato pode ser parcialmente relacionado com as diferenças na composição racial dos rebanhos. Os sistemas especializado (ES), semi-especializado (SE) e o não-especializado (NE) possuíam, respectivamente, os seguintes números de rebanhos das raças Jersey e Holandesa: 1 e 2 (ES), 1 e 3 (SE) e 1 e 1 (NE). O leite da raça Jersey possui mais sólidos totais que o da raça Holandesa (FONSECA \& SANTOS, 2000; ZANELA et al., 2006). Segundo PEREIRA et al. (1997), a diminuição no volume de produção de leite pode aumentar a concentração dos seus componentes químicos, devido a um menor efeito de diluição. Dessa forma, o número desigual de unidades de produção leiteira com rebanhos da raça Holandesa e as diferenças numéricas de produção leiteira entre os sistemas podem ter contribuído para a ausência de diferença estatística para os componentes químicos do leite dos sistemas de produção considerados.

Esses resultados diferem dos dados de GONZALEZ (2002) e dos de ZANELA et al. (2006), que encontraram diferenças entre os sistemas para as 
Tabela 2 - Valores médios da composição química da dieta agrupados por sistemas de produção no início, meio e fim do período de estudo.

\begin{tabular}{|c|c|c|c|c|c|c|c|c|c|}
\hline & \multicolumn{3}{|c|}{ outubro/2001 } & \multicolumn{3}{|c|}{ março/2002 } & \multicolumn{3}{|c|}{ agosto/2002 } \\
\hline & ES & SE & $\mathrm{NE}$ & ES & SE & NE & ES & SE & $\mathrm{NE}$ \\
\hline \multicolumn{10}{|c|}{ Pastagem } \\
\hline PB & 12,30 & 9,56 & 9,40 & 9,63 & 8,23 & 8,19 & 13,03 & 14,64 & 12,85 \\
\hline FDN $^{1}$ & 57,82 & 60,97 & 63,56 & 71,38 & 72,51 & 74,27 & 56,68 & 58,48 & 61,25 \\
\hline FDA $^{2}$ & 40,87 & 46,96 & 43,79 & 41,42 & 40,22 & 41,04 & 36,67 & 31,13 & 43,73 \\
\hline \multicolumn{10}{|c|}{ Concentrado } \\
\hline $\mathrm{PB}^{3}$ & 15,12 & 15,68 & 15,01 & 18,59 & 16,47 & 14,36 & 16,70 & 15,01 & 14,05 \\
\hline FDN & 30,86 & 36,86 & 37,13 & 43,86 & 44,25 & 41,11 & 33,70 & 35,95 & 36,28 \\
\hline FDA & 9,23 & 8,07 & 16,64 & 11,10 & 16,40 & 17,23 & 13,72 & 16,78 & 14,59 \\
\hline \multicolumn{10}{|c|}{ Silagem } \\
\hline PB & 5,74 & - & - & 6,90 & - & - & 6,02 & - & - \\
\hline FDN & 62,03 & - & - & 64,13 & - & - & 61,72 & - & - \\
\hline FDA & 33,85 & - & - & 33,93 & - & - & 38,07 & - & - \\
\hline
\end{tabular}

${ }^{1}$ Fibra em detergente neutro (FDN), valores expressos como porcentagem da matéria seca.

${ }^{2}$ Fibra em detergente ácido (FDA), valores expressos como porcentagem da matéria seca.

${ }^{3}$ Proteína Bruta (PB), valores expressos como porcentagem da matéria seca.

percentagens de gordura, lactose, extrato seco total e extrato seco desengordurado. Da mesma forma, ALLORE et al. (1997) encontraram diferenças quanto aos teores de proteína, caseína e nitrogênio nãoprotéico no leite proveniente de rebanhos sob diferentes manejos nutricionais no inverno.

O valor de contagem de células somáticas (CCS) não diferiu entre os sistemas, embora o percentual de mastite tenha aumentado à medida que o grau de especialização diminuiu (Tabela 1 ). As vacas leiteiras convivem em seu ambiente com uma vasta gama de microrganismos e é inevitável que alguns deles entrem na glândula mamária e causem mastite (PHILPOT, 2002). A nutrição, o manejo, a higiene e as condições ambientais foram citadas por MENDONÇA et al. (1999) como fatores que influenciam a capacidade do hospedeiro em responder às agressões. O Corynebacterium bovis é o agente de maior prevalência na região sul do Rio Grande do Sul, correspondendo a cerca de $50 \%$ dos quartos que apresentaram crescimento microbiológico positivo (RIBEIRO et al., 2002). Em termos de patogenia, esse agente apresenta limitada virulência, determinando um pequeno aumento na CCS em torno de 300 a 400 mil cél./mL (FONSECA \& SANTOS, 2000).

Compararam-se os valores de contagem de células somáticas (CCS), proteína (PB), gordura (GB) e extrato seco desengordurado (ESD) encontrados com aqueles preconizados pela Instrução normativa 51 (BRASIL, 2002) até julho de 2008. O sistema NE apresentou maior percentual de amostras com CCS acima do limite, o que possivelmente está relacionado ao deficiente controle da mastite. Todos os sistemas apresentaram elevados percentuais de amostras fora dos padrões para as concentrações de gordura, de proteína e de extrato seco desengordurado, segundo a IN51 (Tabela 1). Esse resultado indica a existência de diferenças regionais importantes que não foram levadas em conta pela IN51, e, talvez, a necessidade de melhorarse o manejo nutricional e sanitário dos rebanhos em todos os sistemas de produção.

\section{CONCLUSÕES}

A melhoria das condições sanitárias conferidas pelo sistema especializado reduziu a ocorrência de mastite nos rebanhos. Boa parcela das amostras de leite não se enquadram nos limites estabelecidos pela IN51.

\section{REFERÊNCIAS}

ALLORE, H.G. et al. Effects of seasonal, herd size, and geografic region on the composition and quality of milk in the Northeast. Journal of Dairy Science, v.80, n.12, p.3040-3049, 1997.

AOAC. Official methods of analysis. 12.ed. Washington, DC, 1975. 1094p.

BENTLEY INSTRUMENTS. Bentley 2000: operator's manual. Chaska, 1995a. 77p.

BENTLEY INSTRUMENTS. Somacount 300: operator's manual. Chaska, 1995b. 12p.

BITENCOURT, D. et al. Sistemas de pecuária de leite: uma visão na região de Clima Temperado. Pelotas: Embrapa Clima Temperado, 2000. 195p.

Ciência Rural, v.37, n.1, jan-fev, 2007. 
BRASIL. Instrução Normativa $n^{\circ} 51$, de 20 de setembro de 2002. Aprova os regulamentos técnicos de produção, identidade e qualidade do leite tipo... Diário Oficial da União, Brasília, p.13, 21 set. 2002. Seção 1.

FAGUNDES, C.M. Inibidores e controle da qualidade do leite. Pelotas:UFPEL, 1997. 126p.

FONSECA, L.F.L.; SANTOS, M.V. Qualidade do leite e controle de mastite. São Paulo: Lemos Editorial, 2000. 175p.

GOERING, H.K., VAN SOEST, P.J. Forage fiber analysis (apparatus, reagents, procedures and some aplications). Washington, DC.: Agricultural Research Service, US. Dep Agric, 1970. 79p.

GONZALEZ, H.L. Qualidade do leite em diferentes sistemas de produção e meses do ano na bacia leiteira de Pelotas. 2002. 120f. Dissertação (Mestrado em Zootecnia) - Programa de Pós-graduação em Zootecnia, Universidade Federal de Pelotas.

MARKUS, R. Elementos da estatística aplicada. Porto Alegre: Faculdade de Agronomia, Universidade Federal do Rio Grande do Sul, Diretório Acadêmico Leopoldo Cortês, 1973. 329p.

MARTINS, P.R.G. et al. Produção e qualidade do leite na bacia leiteira de Pelotas-RS em diferentes meses do ano. Ciência Rural, v.36, n.1, p.209-214, 2006.

MENDONÇA, C.L. et al. Etiologia da mastite bovina. Veterinária Notícias, Uberlândia, v.5, n.1, p.107-118, 1999.

MONARDES, H. Reflexões sobre a qualidade do leite. In: DÜRR, J.W. et al. O compromisso com a qualidade do leite no Brasil. 1. Passo Fundo: UPF, 2004. 331p.

NATIONAL RESEARCH COUNCIL - NRC. Nutrient requirements of dairy cattle. 7. Washington, DC.: National Academic, 2001. 381p.

NG-KWAI-HANG, K.F. et al. Environmental influences on protein content and composition of bovine milk. Journal of Dairy Science, v.65, p.1993-1998, 1982

PEREIRA, A.R. et al. Contagem de células somáticas e qualidade do leite. Revista dos Criadores, v.67, n.807, p.19-21, 1997.
PHILPOT, W.N. Qualidade do leite e controle de mastite: passado, presente e futuro. In: CONGRESSO PANAMERICANO DE QUALIDADE DO LEITE E CONTROLE DE MASTITE, 2., 2002, Ribeirão Preto-SP. Anais... Ribeirão Preto-SP: Instituto Fernando Costa, 2002. p.23-38.

RIBEIRO, M.E.R. et al. Qualidade de leite. In: BITENCOURT, D. et al. Sistemas de pecuária de leite: uma visão na região de clima temperado. Pelotas: Embrapa Clima Temperado, 2000. p.174-195.

RIBEIRO, M.E.R. et al. Microbiological characteristics of mastitis and reaction to CMT test of a Jersey herd under a correct milking management. In: CONGRESSO PANAMERICANO DE QUALIDADE DO LEITE E CONTROLE DE MASTITE, 2., 2002, Ribeirão Preto-SP. Anais... Ribeirão Preto-SP: Instituto Fernando Costa, 2002. p.75-78.

RIBEIRO, M.E.R. et al. Sistema de produção. In: BITENCOURT D. et al. Sistemas de pecuária de leite: uma visão na região de clima temperado. Pelotas: Embrapa Clima Temperado, 2000. p.175-195.

RODRIGUES, P.H.M. Fatores não microbiológicos afetando acidez do leite e outras características. In: CURSO ONLINE SOBRE QUALIDADE DE LEITE, Cap. 4. Acesso em 20 de ago. 2000. On line. Disponível na Internet: http:// www.milkpoint.com.br.

SAS. SAS/STAT User's guide, version 6. 4.ed. Cary, NC: SAS Institute, 1989. 657p.

SCHALM, O.W.; NOORLANDER, D.O. Experimental and observation lading to development of California Mastitis Test. Journal of Animal Veterinary Medicine, v.130, p.199204, 1957

SILVA, P.H.F. et al. Físico-química do leite e derivados métodos analíticos. Juiz de Fora: Oficina de Impressão Gráfica, 1997. 190p.

TRONCO, V.M. Manual para inspeção da qualidade do leite. Santa Maria: UFSM, 1997. 166p.

ZANELA, M. B. et al. Qualidade do leite em sistemas de produção na região sul do Rio Grande do Sul. Pesquisa Agropecuária Brasileira, v.41, n.1, p.153-159, 2006 